\title{
LIVING CHANGED LIVES: EXPERIENCES OF INDIVIDUALS AFTER ORAL RECONSTRUCTIVE SURGERY
}

\author{
Janine Rose P. Sablada ${ }^{1}$ and Mauro Allan P. Amparado ${ }^{2}$
}

(1) Nurse I, Isidro C. Kintanar Memorial Hospital, Argao, Cebu, Philippines; jahninerose86@yahoo.com

(2) Professor, Graduate School, University of Cebu, Cebu City, Cebu, Philippines; http://orcid.org/0000-0002-2742-2508; mapamparado@gmail.com

\begin{abstract}
The study delved into the experiences of individuals who underwent oral reconstructive surgery. The informants were interviewed on their experiences before, during and after surgery. The psychological and physical impact were also derived from the informants' experiences. The phenomenological research design was utilized in the study. There were four informants in this study with orofacial deformity who underwent oral reconstructive surgery. Informants were purposively selected by the researchers. It was conducted in selected areas of Argao, Cebu, Philippines. The researchers interviewed three of the informants in their respective homes and one informant in his workplace. The researchers utilized an unstructured interview guide. Colaizzi's phenomenological method of data analysis was utilized to interpret data and to identify meaningful information and organize it into themes or categories.

Based on the findings, eight themes emerged: When teasing becomes hurtful and unkind; Finding the courage isn't easy to do; Chance of a lifetime; I am cared; Expecting congenital deformity of offspring; Surgery as key to social acceptance; Surgery as fountainhead of true happiness; A new image of oneself.
\end{abstract}

Keywords: Living Changed Lives; Cleft lip and palate; Oral reconstructive surgery; Physical impact; Psychosocial impact; Argao, Cebu, Philippines.

\section{Background}

Cleft lip and palate affect about 1.5 per 1000 live births worldwide. This is considered a debilitating condition associated with feeding, hearing, speech, and psychological impairments. In the Philippines, majority of the less fortunate individuals who are affected with this deformity have difficulty in accepting themselves. They feel that their condition has no hope and cure. Most of them do not finish their studies because of the visible deformity and speech difficulty. Some do not pursue activities and isolate themselves from the public.

There are non-government organizations which provide free and safe surgery to individuals who have cleft lip and palate. One of these organizations is Operation Smile Philippines. It has provided free reconstructive surgery to Filipinos for more than thirty-three years. In Cebu City, their surgical missions are conducted in partnership with tertiary hospitals.

In December 2016, a surgical mission was conducted at Isidro C. Kintanar Memorial Hospital for cleft lip and cleft palate patients. There were 39 cases who successfully underwent cheiloplasty and palatoplasty. These patients came from different parts of Southern Cebu. 
This study is anchored on Merle Mishel's Uncertainty in Illness Theory. According to Mishel, a person with an illness will experience uncertainty if he/she fails to determine the meaning of illness-related events. Uncertainty is ambiguous, complex, and unpredictable. According to this theory, people with illness will develop subjective evaluations to assist them in interpreting the experience of illness and treatment. Uncertainty occurs when the person is unable to predict the outcomes of illness and treatment, or he/she is unable to assign a definite value to objects or events while he/she is ill (Alligood \& Tomey, 2010.

There are three major themes in this theory: antecedents of uncertainty, appraisal of uncertainty, and coping with uncertainty. The ideas included in the antecedent theme of the theory include stimuli frame, cognitive capacity, and structure providers. Stimuli frame is defined as the form, composition, and structure of the stimuli that the person perceives. Cognitive capacity is the information processing ability of the individual, Structure providers are the resources available to assist the person in the interpretation of the stimuli frame.

The second major theme is the appraisal of uncertainty, which is defined as the process of placing a value on the uncertain event or situation. The third theme is coping with uncertainty, and the concepts include danger, opportunity, coping, and adaptation. The danger is the possibility of a harmful outcome. Opportunity is the possibility of a positive outcome. Coping with a danger appraisal is defined as activities directed toward reducing uncertainty and managing the emotions generated by a danger appraisal. Coping with an opportunity appraisal is defined as activities directed towards maintaining uncertainty. Adaptation is defined as biophysical behavior occurring within a person's individually defined range of usual behavior (Alligood \& Tomey, 2010; Smith \& Liehr, 2008).

Cleft lip is a disorder which ranges from a small notch in the upper lip to the total separation of the lip and facial structure up into the floor of the nose. The upper teeth and gingiva are absent. Cleft palate is an opening of the palate usually on the midline. It may involve the anterior hard palate, the posterior soft palate, or both (Pilliteri, 2010).

To date, there is little understanding of the complex genetic and cellular mechanisms required for normal orofacial development. Higher rates of oral clefting are due to exposure to alcohol, cigarette smoking, anti-convulsants, steroids, retinoids, and folate deficiency. During facial development, five structures are involved in the growth of the fetal face: the median frontonasal prominence, the paired maxillary prominences, and the paired mandibular prominences. When the developmental processes of these structures fail, orofacial clefts can result (Abbott, 2014; Perry et al., 2014).

Cleft lip and palate are usually diagnosed at birth or during the newborn assessment. Because speech, hearing, and dentition may be affected, coordinated care by specialists in plastic surgery, hearing, speech, and dentistry is necessary. The team may also include specialized individuals such as orthodontics, oral surgery, pediatric dentistry, prosthodontics, genetics, otolaryngology, pediatrics, plastic surgery, psychiatry, audiology, nursing, psychology, social work, and speech pathology. These healthcare providers evaluate the patient's medical status, general development, dental development, facial esthetics, psychological well-being, hearing, and speech development (Jones et al., 2011; Ladewig et al., 2007).

The cleft lip is usually repaired around three months of age. The lip is sutured together using either a diagonal incision or a staggered suture line. If the defect is severe, it may need 
more than one operation to achieve the total repair. For cleft palate, most surgeons perform closure operations before 18 months of age. This prevents the formation of tooth buds and allows the infant to develop more normal speech patterns (London et al., 2014).

There are three phases in a surgical experience: preoperative, intraoperative, and postoperative. As the patient is notified of the demand for surgery, it is important for doctors, nurses and the rest of the surgical team to provide teaching, patient support, and preparation for the procedure. When the patient is transported to the operating room, activities comprise of patient safety, facilitation of the surgical procedure, prevention of infection, and adequate physiologic response to anesthesia and surgical intervention. Then the patient is transferred to the post-anesthesia care unit (PACU) or another area where immediate post-surgical recovery care is given. Finally, the patient is moved to the recovery unit and ends with the resolution of surgical sequelae. It focuses on strengthening the necessary information required in preparation for the discharge of the patient (Goodman \& Spry, 2017).

Various studies have been conducted on cleft lip and cleft palate. Some published studies have focused on the physical aspects while other studies have focused on the psychosocial aspects. In one study, the researchers believed that not all patients experience the benefits of a well-trained multi-disciplinary cleft team. A notable number of patients reach adulthood with severe neglected cleft-related problems. Majority of this group manage to have surgical procedures that are conducted by different surgeons in different centers. An aggressive surgical plan focused mainly on the deformities that can objectively achieve functional and aesthetical improvement should be individualized for each patient (Felemovicius and OrtizMonasterio, 2004).

In another study, Obiri-Yeboah et al. (2016) used a retrospective view of adult/adolescent cleft lip repair under local anesthesia. Majority of them were allowed to go home on the same day, and five of them has to stay overnight because of distance from their home. There were no reported early postoperative complications for all the patients. The study concluded that it is safe, effective, and less expensive to repair the lip under local anesthesia.

Papamanou et al (2012) analyzed the appreciative assessment of head photographs of individuals with treated clefts by lay people and professionals and to investigate how accurate this could be to their result. Five standardized head photos (frontal, both laterals, three-quarter right, and left) of patients with treated unilateral cleft lip and palate were presented to lay people, orthodontist, and maxillofacial surgeons. Each panel of raters has a high level of understanding for all assessments. Compared to professionals, lay people were less satisfied with lip and nose aesthetics. Professionals report have higher satisfaction from the treatment result and evaluate cleft outcomes than lay people. The findings revealed that lay people appreciate the positions of the lip while the specialists focused on the features of the face.

In the study of Hunt et al., (2005), the majority of children and adults with cleft lip and palate do not appear to experience major psychosocial problems. Although some problems may arise such as satisfaction with appearance, anxiety, behavioral problems, attachment, learning problems, interpersonal relationships, and depression.

Teasing was greater among participants who had cleft lip and/ or palate and it was a significant predictor of poorer psychosocial functioning. Children and young adults with cleft lip and/or palate require psychological assessment, specifically focusing on their experience of teasing, as part of their routine cleft care (Hunt et al., 2006). 
In another study, patients and caregivers attribute positive changes related to cleft surgery. Outcomes research requires cooperation with local professionals who can communicate effectively. These data serve to demonstrate feasibility and as a model for future studies of treatment outcomes in follow-up to international medical missions (Sharp et al., 2008).

Although many studies have been conducted on cleft lip and palate and their physical and psychosocial impact, the researchers were inspired to delve into the lives of these individuals before, during, and after oral reconstructive surgery interviewing informants in Argao, Cebu, Philippines. This study hopes to improve the care and help people find meaning in their repaired lives.

\section{Objectives}

This study delved into the experiences of individuals who underwent oral reconstructive surgery in Argao, Cebu, Philippines. The informants were interviewed on their experiences before, during and after surgery. The psychological and physical impact were also derived from the informants' experiences.

\section{Methods}

The phenomenological design was used in the study. This study was conducted in selected areas of Argao, Cebu, Philippines. Argao is in the southeast part of the province of Cebu. It is 68 kilometers from Cebu City and has 45 barangays. The researchers interviewed three of the respondents in their respective homes and one informant in his workplace.

The four informants of the study were of legal age, with orofacial deformity (cleft lip and cleft palate/cleft lip only/cleft palate only) who underwent oral reconstructive surgery. Three of the informants had cleft lip and palate and one with cleft lip only. Two of the three informants with cleft lip and palate underwent cheiloplasty only, and one had both cheiloplasty and palatoplasty. The fourth informant had cleft lip and underwent cheiloplasty.

Informant Red is a 64-year old male with cleft lip and palate who had repair of lip only when he was 13 years old. He is married with three children, a resident of Bulasa, Argao, Cebu and works as an Administrative Aide I in Rural Health Unit I, Argao, Cebu.

Informant Yellow is a 34-year old male with cleft lip and palate who had repair of lip only for three times. He was 7 years old when he had his first operation. Married for three years with two children, a resident of Bulasa, Argao, Cebu and works part-time in a government agency. He is a tricycle driver at the same time.

Informant Green is a 30-year old female with cleft lip and palate who had repair of both lip and palate. Her lip was repaired when she was 7 years old and her palate when she was 12 years old. She is married with one offspring, a resident of Poblacion, Argao, Cebu and works as a midwife in a lying-in clinic.

Informant Black is a 30-year old female with cleft lip only who had repair of her lips when she was 10 years old. She is a single mother of one, a resident of Poblacion, Argao, Cebu and works as an accountant. 
The researchers utilized an unstructured interview guide. The interviews were done from May 10, 2017 to August 10, 2017. Written consent was obtained from each informant prior to the interviews. Colaizzi's phenomenological method of data analysis was utilized to interpret data and to identify meaningful information and organize it into categories. During the data analysis, the researchers transcribed all the informants' description. Significant statements were extracted, the formulated meaning was created and clustered into themes. Exhaustive descriptions were developed and the researchers interpreted the symbolic representations. Finally, the fundamental structure of the phenomenon was identified and validation was done with informants.

This research has met ethical considerations concerning confidentiality, anonymity, freedom to withdraw, informed consent, and freedom from an inquiry. The trustworthiness of this study was ensured with credibility, dependability, transferability, and confirmability. Interview guide was used by the researchers and reviewed by panelists. There were twelve interview sessions held for six 60 minutes per session with the informants. The interview was transcribed and audio-taped with the informants' consent. Validation of transcriptions was checked with the informants. Saturated data were described as results of the study. Data were reviewed with the recorded interview for the formulation of themes.

\section{Results}

There were eight common themes derived from the one-on-one interview. Each informant was interviewed for 12 sessions, 60 minutes per session. Interviews were audiotaped and transcribed. Validation was conducted together with the informants.

\section{Theme 1: When teasing becomes hurtful and unkind}

Because of the visible deformity, these informants experienced being teased at school or in the community. This experience led the informants to skip or stop going to school. Informants pointed out that because of constant teasing, they opted to isolate themselves from others. They prefer not to mingle with others to avoid social discrimination. Informants described their physical appearance when looking at the mirror. Most of them pity themselves because of the visible notch on their lips. Informant Red recalled:

"I went to school before my operation, and I was bullied.

That is why I quit school, then I went back again and then quit again. But I was able to finish Elementary. I do not like being teased. I would rather be on my own. I do not like going with them because I am the only person they would look at. I get offended. When I look in the mirror I get really upset, whatever I do, whichever angle, it is still the same."

With a low-toned voice, Informant Yellow shared:

"They would tease me cleft lip, cleft lip! Every time I would look at myself in the mirror it feels like there is a break within me, and it gets me down. No matter how often I look at myself in the mirror, it still looks the same. How I wish it will change instantly, which only happens in movies (laughs)." 
While informant Green responded:

"I stopped going to school because of all the teasing. Before, I just stay at home all the time. I do not like going out because they would always tease me. In school, there was never a day that I did not cry because they would tease me that I have a cleft lip. I am always embarrassed. I look at myself like I am an inadequate individual. I feel sorry for myself every time I look in the mirror."

And informant Black was teary-eyed as she stated:

"People teased me a lot since first grade to fourth grade because they have seen that I am different. My lips look like it has a dent. When I was still in school, I avoid my classmates, because for me, I am different from them. I do not look at myself in the mirror. Since there are times that we cannot avoid to look in the mirror, what I do is to do glances while looking at the mirror."

\section{Finding the courage isn't easy to do}

Knowing that they are labeled differently from others results in low self-esteem, selfconfidence, and social isolation. At their young age, they were told by their loved ones to find the courage. Informant Red remembered:

"Whenever my father has guests, I would hide behind the door, or at the back of curtains because I am embarrassed to present myself to them."

Informant Yellow explained:

"I was really ashamed of my facial defects. They would tease me and I could not accept myself for that, that is why I stopped going to school."

Informant Green admitted that:

"I have low self-esteem before. I can't manage to talk to other people before especially if I am not comfortable with them."

\section{Chance of a lifetime}

In the case of these informants, all of them underwent orofacial surgery before reaching 14 years old. Because of limited financial resources and access to surgical repair, they availed of free surgical missions performed in tertiary hospitals in Cebu City. Surgical missions led by non-government organizations usually coordinate with the rural health units. Informants acquire information through their village (barangay) health workers or rural health midwives. Some also acquired the information through an announcement at the municipal hall. 
The informants shared the details of when and how they were able to access the free repair for their orofacial deformity. Informant Red remembered:

"I had my surgery in Cebu City at Southern Islands Hospital. I was 13 years old. There were midwives who went around the village announcing of the free surgical mission. They informed my mom about the procedures for the free surgery."

Informant Yellow was smiling as he shared that,

"I was seven years old when I had my surgery at the Memorial Hospital and then I also had another one in Vicente Sotto Hospital. I had three surgeries all for free, done by surgical missions. The midwife went to our house and informed my mom about the free surgery. It was announced by the municipal hall and Department of Social Welfare and Development. They would always announce these free surgeries. I was really happy about the surgery. Who wouldn't be, thinking that the hole on my lip will be closed."

Informant Green felt fortunate as she said:

"I got operated on my lips when I was seven years old. My palate was operated when I was twelve years old. Both surgeries were done for free since my mom is working in the rural health unit. She reports there every day. She easily gets information about surgical missions."

As a beneficiary of the free surgery, Informant Black was ecstatic when she knew that there is a solution to her problem. She narrated:

"I had my surgery when I was ten years old. There was a surgical mission in our area, and my mom was approached by the village health worker. She was told that there would be a free reconstructive surgery for cleft lip and cleft palate in the city. I was really happy because there is already a cure for my cleft lip."

Before the operation, screening was done first. According to the informants, the experience was not easy since it was conducted in Cebu City, the capital city of Cebu. At a young age, Informant Yellow shared the concerns on expenses during the screening, as he stated:

"Screening is exhausting. You have to return from time to time, and travel back and forth. It would not matter if we were rich, but unfortunately, we are not."

Informant Black shared,

"It was a little exhausting traveling back and forth to the city.

I had blood extractions and other laboratory tests." 


\section{Informant Green narrated:}

"Before the surgery, all patients and our parents were informed of what is expected to happen and what are the do's and don'ts. The staff were all nice even if some of them are not Filipinos."

On the day of the surgery, informants remembered that they were sedated, and when they woke up, the operation was done. Informant Green narrates:

"They have explained the procedures well and they were all friendly. They are used to handling these cases. Everything went well. They put me to sleep. The place was cold and very clean."

And Informant Black stated that:

"They injected something on my IV that made me fall asleep. When I woke up, the surgery was done. I was in pain. The medical was very supportive."

\section{I am cared}

The entire perioperative experience of the informants was supported by their family members. Post-operatively, the mothers of the informants were the primary caregivers. They were instructed and informed on what to expect during and after surgery. The wound dressing of the post-operative site was done by their mothers. Informant Red recalled:

"I can remember my mom talking to a guy wearing white, he was probably a doctor. My mom told me not to laugh so hard because the stitches on my lips might re-open. I was also given take home medications. We would go to the village health center for the dressing of my surgical wound."

Informant Yellow shared:

"We were advised to clean the suture and to eat slowly. My mom would clean my wound."

Informant Green was smiling when she answered:

"I was very excited to go home because the surgery was already done. They have told my mom what should be done and what's not. There were also instructions about the medication. My mom cleans my surgical wound."

Informant Black shared:

"My mom told me that the doctor instructed us to avoid too 
much activity and not to laugh so much because the sutures might re-open. When we got home, my mom would do the dressing of my wounds. She would also allow me to see myself in a mirror."

\section{Expecting congenital deformity of offspring}

Even though two of the informants were not able to have completely repaired their deformity, all of them have been living the life they dreamed of. Despite all of the struggles and challenges they have encountered, all informants in this study have created their respective families. Three are married and one is a single parent. All of them are blessed with a child or children.

Informant Red has three children who are adults and independently living on their own. He shared how he courted his wife and found love:

"I was skeptical if she will say yes when I courted her. I told myself to try. If she agrees, well and good. If not, it is fine as well. Nobody was ever sent to prison because of this. I courted, and she said yes. When my wife got pregnant, I was anxious of the fact that my child might have the same defect. I was always thinking about it and kept it to myself. I was thinking, if my child will have the same defect, I will be the first person to support my child during the surgery. I was very happy when my child was born. He was healthy with no defects. If he had the same defect, I will anticipate teasing from friends. Then I might get into trouble. I am just glad my child has no defects."

During the interview sessions, Informant Yellow revealed that he has two sons. One was 3 years old while the other is 3 months old. He shared:

"Love life? Of course, I have a very good love life. She was a vendor and my uncle who serves as the village leader would request me to buy goods in the shop where my wife works. I became a regular customer. Later, I courted her and she accepted me. We fell in love and I married her. But I was anxious when she got pregnant. I was afraid that my child will have the same defect. I prayed for my child to be healthy. I would not want him to go through what I have experienced in the past."

Informant Green is married to a seafarer. She met her husband through a common friend. She recalled:

"I was introduced to my husband by my friend. At first, I refused to meet him. I was ashamed of my defect. But he courted me. He was a fine man. By the time I was pregnant, I was always thinking if my child will have the same defect. When my child was born, the first thing I did was to check my child's nose, mouth, hands and feet. I was relieved to see that my child was physically normal.” 
Informant Black, a single mother, was hesitant to share her love life. She told us that she would not like to talk about her ex-husband, but she revealed:

"When I was pregnant, I was afraid that my child will have the same defect as mine. It might be genetically inherited. I was anxious for nine months. But I was very happy to find out that my child was physically normal."

\section{Surgery as key to social acceptance}

To be accepted in a group or a community is essential for humans. For our informants, the free surgery made them acceptable to a community that labeled them as different. Informant Red said:

"After the surgery, I started to have more friends. They would bring me along with them to celebrate occasions or when we visit a place. Now, I can be who I want to be. I have freedom."

Informant Yellow was thankful because despite his speech difficulty, he was able to gain respect of others after the surgery:

"I was able to gain the respect of my peers. Although I

still have speech difficulties, the physical appearance has greatly improved."

For Informant Green and Informant Black, they shared their experiences at school after the surgery. Informant Green narrated:

"Prior to surgery, my classmates would tease me. Most of the time, I would be alone. After the surgery, I was more participative in class and in school activities. I have gained more friends."

Informant Black shared:

"I volunteered in school activities. I also joined competitions and represented my school. After the surgery, I gained confidence and I was ready to accept responsibilities in school."

\section{Surgery as fountainhead of true happiness}

Being beneficiaries of free surgeries is a turning point in the lives of these informants. After the surgery, they claimed that they are more outgoing. It gave them hope and a chance to live their lives to the fullest.

"What more could I ask for? The surgery is free. I am glad that there are organizations which provide these free services and outreach programs. I feel that I am no longer left behind. I will not be able to hear hurting words. People see me now as a person with no defect." - Informant Yellow. 
"I am no longer ashamed. I can go out and be with the crowd. I have accepted myself. I am contented. Now, I have three children, all of them have finished school. I am about to retire, maybe last quarter of the year." - Informant Red.

"The surgery helped me a lot. I wouldn't be successful if I didn't go through this surgery. It gave me the hope to continue life and pursue my dreams and aspirations in life." - Informant Green.

"My surgery helped me so much because I was able to accept myself. I have achieved everything I have now because of it. It helped boost my self-esteem and confidence. If I have not gone through the surgery before, I would still have this cleft lip today." - Informant Black

\section{A new image of oneself}

Our informants received good comments regarding the physical change after surgery. The informants were satisfied with the results as well.

"Some of my friends said I am handsome. I have never heard that before. Now, I keep on looking at myself in the mirror. It has changed my facial features." - Informant Red.

"The first person who said I was handsome was my nurse. I looked at the mirror, and I am pleased with what I see." Informant Yellow.

\section{Discussion}

The physical and psychological impact is very evident as the informants' experiences moved from the time they were discriminated as individuals with cleft lip and cleft palate, to a phase when the oral reconstructive surgery was completed, and a phase when they have improved their facial features after the surgery. The researchers have felt the pain and self-pity experienced by the informants as people see their defects. The harsh words heard from classmates and friends has led them to isolate themselves from others. Persons with cleft lip and palate experience psychological and social concerns due to their appearance. This is strengthened by one study which hypothesized that faces with cleft lip and palate were looked negatively compared with regular faces. Using an eye-tracking camera, the participants of the study were observed while viewing photographs of faces with or without cleft lip and palate. The participants also rated the face appearance, symmetry, and facial expression of the photographs. The faces with cleft lip and palate, have significant staring in the mouth and more extended staring in mouth and nose areas. Moreover, the participants rated the cleft lip and palate faces negatively (Meyer-Marcotty et al., 2010.

Surgery results in increasing the satisfaction, self confidence and esteem of individuals with orofacial defects. In our study, this is evident when informants have appreciated their physical features with the use of mirrors. However, it is necessary for oneself to develop positive self-skills to deal with situations. According to De Sousa et al. (2009), acceptance can 
be achieved if an individual has adopted these skills, generate positive social interaction skills, display social competence, and be less likely to exhibit significant adjustment problems. High and unrealistic expectations after the surgery may also lead to dissatisfaction.

As soon as the surgery is completed, we have gathered information from the informants that their mothers have been their primary caregivers. Significantly, the health teachings of the medical team and discharge instructions were considered by the informants and caregivers as vital tools to achieve optimal wellness. Similar to the study of Jalang \& Amparado (2017), the researchers revealed that it is essential for patients and their significant others to comply with discharge instructions. Discharge instructions may include treatment, procedures, medications, exercise, and diet. This ensures that the recovery and wellness of a person is achieved at the soonest possible time.

The study also revealed positive outcomes of the surgery by improving the physical features of the informants and boosting their self-image, hence making them more participative and productive on a day to day basis. According to the study of Beluci \& Genaro (2016), surgical correction of dentofacial deformity improved quality of life and had positive impact of oral health condition.

Similarly, Munz et al., (2011) discovered that patients reported a positive oral healthrelated quality of life. Patient and parent treatment satisfaction was related. Patients' oral health-related quality of life scores correlated with parent and patient treatment satisfaction and parents' outcome satisfaction. In conclusion, regardless of outcome satisfaction, young patients with cleft lip and palate report a quite positive oral health-related quality of life after treatment completion.

\section{Conclusion}

Based on the common themes of the study, it is important for the government and nongovernment organizations to continue providing free oral reconstructive surgery for individuals with cleft lip and palate. They have limited resources and access to surgery. With surgical missions conducted by the government and non-government organizations, less fortunate individuals will have the opportunity to have a positive outlook in life. It is vital for the perioperative team to provide sufficient information to patients of what to expect before, during and after the surgery. Village health workers and rural health midwives have essential roles to disseminate to prospective candidates for orofacial surgery timely information regarding free surgical operations.

The study also advocates mothers to take good care of themselves and ensure a healthy pregnancy especially in areas where there is limited access to health services. Smoking, alcohol use, and drug addiction during pregnancy are some of the predisposing factors for orofacial defects.

This study gives us insights on the experiences of individuals with cleft lip and palate on discrimination and their desire for social acceptance and support from the society. It is important for a community to have a genetic counseling unit which will facilitate the counseling needs of persons with physical abnormalities and educate women on a healthy lifestyle during pregnancy. Finally, this study recommends to future researchers the continuous exploration of stigma, discrimination and bullying to individuals with orofacial defects. 


\section{References}

Abbott, M. A. (2014). Cleft lip and palate. Pediatrics in review, American Academy of Pediatrics, 35(5), 177.

Alligood, M. R. \& Tomey, A. M. (2010). Nursing theorists and their work. $7^{\text {th }}$ edition. Singapore: Mosby Elsevier.

Beluci, M. L., \& Genaro, K. F. (2016). Quality of life of individuals with cleft lip and palate pre-and post-surgical correction of dentofacial deformity. Revista da Escola de Enfermagem da USP, 50(2), 217-223.

De Sousa, A., Devare, S. \& Ghanshani, J. (2009). Psychological issues in cleft lip and cleft palate. Journal of Indian Association of Pediatric Surgeons, 14(2), 55.

Felemovicius, J. \& Ortiz-Monasterio, F. (2004). Management of the impaired adult cleft patient: The last chance. The Cleft Palate-Craniofacial Journal, 41(5), 550-558.

Goodman, T. \& Spry, C. (2017). Essentials of perioperative nursing. $6^{\text {th }}$ edition. Singapore: Jones \& Barlett Learning.

Hunt, O., Burden, D., Hepper, P., \& Johnston, C. (2005). The psychosocial effects of cleft lip and palate: a systematic review. European journal of orthodontics, 27(3), 274-285.

Hunt, O., Burden, D., Hepper, P., Stevenson, M., \& Johnston, C. (2006). Self-reports of psychosocial functioning among children and young adults with cleft lip and palate. The Cleft palate-craniofacial journal, 43(5), 598-605.

Jalang, J. D. R. \& Amparado, M. A. P. (2017). Compliance with discharge instructions among Prostatectomy patients. IAMURE International Journal of Social Sciences, 19(1), 39-57.

Jones, J. E., Sadove, A. M., Dean, J. A., \& Huebener, D. V. (2011). Multidisciplinary team approach to cleft lip and palate management in mcDonald and avery dentistry for the child and adolescent. Singapore: Elsevier Inc.

London, M. L., Ladewig, P. W., Ball, J. W., Bindler, R. C., \& Cowen, K. J. (2014). Maternal and child nursing care. $3^{\text {rd }}$ edition. England: Pearson Education Limited.

Meyer-Marcotty, P., Gerdes, A. B. M., Reuther, T., Stellzig-Eisenhauer, A., \& Alpers, G. W. (2010). Persons with cleft lip and palate are looked at differently. Journal of Dental Research, 89(4), 400-404.

Obiri-Yeboah, S., Yeliborah, M., Acheampong, A. O., Ansah, S. K., Grant, J. H. \& Doncor, P. (2016). Adult cleft lip repair under local anaesthesia: The Ghana Experience. Modern Plastic Surgery, 6(4), 27.

Papamanou, D. A., Gkantidis, N., Topouzelis, N., \& Christou, P. (2012). Appreciation of 
cleft lip and palate treatment outcome by professionals and lay people. The European Journal of Orthodontics, 34(5), 553-560.

Perry, S. E., Hockenberry, M. J., Lowdermilk, D. L., \& Wilson, D. (2014). Maternal and child nursing care. Missouri: Elsevier.

Pilliteri, A. (2010). Maternal and child health nursing care of the childbearing and childbearing family. $6^{\text {th }}$ edition. Philadelphia: Lippincott Williams \& Wilkins.

Smith, M. J. \& Liehr, P. R. (Eds). (2008). Middle range theory for nursing. Singapore: Springer Publishing Corporation. 